\title{
Research on Multi-resource Equilibrium Optimization of Construction Project Considering Scheduling Cost
}

\author{
Huijun Huang ${ }^{a}$, Wenjing Zhao \\ School of Economics and Management, Nanjing University of Science and Technology, Nanjing \\ 210094, China \\ a1365953880@qq.com, ${ }^{b} 1150283183 @ q q . c o m$
}

Keywords: multi-resource equalization; resource scheduling cost; genetic algorithm

Abstract: The construction technology of the construction project is complicated, which leads to more resource constraints and resource fluctuations, and reduces the stability and economy of the project construction. This paper constructs a multi-resource equilibrium optimization mathematical model from the perspective of resource scheduling cost, uses genetic algorithm to solve it at the same time, and provides a reference for the multi-resource equilibrium optimization research of construction project construction.

\section{Introduction}

Resource balance optimization refers to the relatively balanced consumption of resources in different periods by reasonably arranging the start time of each work or adjusting the progress of the project when the construction period is determined. So far, the research on multi-resource equilibrium optimization of construction projects has not yet formed a relatively mature theory and method ${ }^{[1]}$.

Based on the theory of resource balance optimization and related research results at home and abroad, this paper summarizes the existing resource balance methods, and proposes a new multi-resource balance optimization index-resource scheduling cost, which aims to build a resource equilibrium optimization model. And use genetic algorithms to perform operations.

\section{Overview of multi-resource balance problems in construction projects}

\subsection{The goal of multi-resource balance optimization}

The multi-resource equilibrium optimization problem is theoretically a kind of combinatorial optimization problem, and its goal is to comprehensively coordinate the start time of each work under the premise of keeping the total project duration unchanged, therefore, the consumption of various resources required for project construction tends to be as balanced as possible throughout the construction period, and the utilization cost of resources in the construction process is minimized, thereby realizing optimal allocation of resources.

Multi-resource balance under modern mechanical construction conditions does not necessarily require that all resources be used to achieve equilibrium simultaneously, and it is impossible to 
achieve equilibrium at the same time, however, several major resources are required to be used as balanced as possible to reduce the high idle costs caused by uneven use. Therefore, multi-resource balance should emphasize the overall balance of major resources, and its ultimate goal is still to reduce construction costs.

\subsection{Defects of traditional multi-resource equilibrium optimization method}

From the existing literature, the current multi-resource equilibrium optimization methods can be roughly divided into two categories: one is to convert multiple resources into single resources; the other is to convert multiple targets into single targets ${ }^{[2]}$. However, the above two methods are limited to the statistical equilibrium to solve the resource equilibrium optimization index, and directly perform simple weighted summation, which does not guarantee that the important resources are preferentially balanced, and the optimization results are uncertain.

From the perspective of cost, research on multi-resource balance of construction projects can avoid the following two problems: First, how to determine the importance of resources ${ }^{[3]}$. The second is the dimensionless treatment of resources. The dimensionless treatment of resources will weaken the practical significance of various resources for project implementation. In this paper, the resource scheduling cost is used as the objective function to carry out multi-resource equilibrium optimization research, which avoids the adverse effects of resource non-dimensionalization.

\subsection{Resource scheduling strategy selection}

In the actual construction of the project, there are two resource scheduling strategies that are often used: Resource Idle (RI), Release and Re-Hire (RH). The resource idle strategy refers to the resource idle demand strategy when the resource demand is at a low level, and the amount of resources that have been hired is kept idle on the construction site until the resource demand increases. The dismissal re-employment strategy refers to the dismissal of redundant resources when the resource demand is lower than the peak demand of resources, and the re-employment of resources when new resource demands arise. This strategy is called the dismissal re-employment strategy. In actual engineering construction, the above two resource scheduling strategies are often used according to the characteristics of different resources. The purpose is to minimize the impact of resource fluctuations on construction costs, and reduce negative Effects resource idle costs or frequent resource scheduling.

\section{Proposal and composition of resource scheduling costs}

The definition of resource scheduling cost in this paper refers to the expenses incurred in order to make the resources function properly at a specific time and at a specific place, including human resource dispatching fees and mechanical dispatching fees.

\subsection{Human resource scheduling costs}

Human resources are the main body of engineering construction, which refers to the sum of the quantity and quality of labor involved in construction projects under certain time and space conditions.

(1) Acquisition costs human resource. It refers to the costs incurred in obtaining or paying for human resources (including all expenses incurred in recruitment, selection, recruitment, fixed posts, etc.),including the loss of efficiency caused by the inefficiency of new employees due to unfamiliarity. 
(2) Development costs of human resource .It refers to the expenses incurred by the project in a variety of ways for the purposeful and planned training and training of employees.It mainly includes two parts: new employee training and safety education costs.

(3) Compensation for human resources. Calculate as follows ${ }^{[4]}$ :

Worm compensation $=$ number of nest workers $\times$ unit price of workers. Number of workers in the nest $=\sum$ number of people in each type of work plan $-\sum$ number of people in each type of work .

\subsection{Mechanical equipment scheduling costs}

There are many types of mechanical equipment in the engineering field, which are widely distributed and have different uses. According to the purpose of the equipment, it can be divided into several types. Due to resource imbalance, the dispatching fee for mechanical equipment resources generally includes mechanical entry and exit fees, equipment installation fees, and machinery idle fees.

(1) Machinery entry and exit fees. It refers to the transfer cost of transportation, loading and unloading, auxiliary materials and overhead of construction machinery from the parking space to the construction site. This calculation is not considered.

(2) Equipment installation fee. It refers to the labor, materials, machinery and commissioning costs required for the installation and disassembly of construction machinery on site, as well as the cost of erection and dismantling of mechanical auxiliary facilities. The corresponding calculation method has been clearly given in this type of cost pricing specification.

(3) Machinery idle fees. Machinery idle fee $=$ number of working machinery $\times$ working machinery station fee. The calculation of the unit price of idle machinery can be divided into two categories: One is the idle mechanical station fee for own equipment; the other is the idle mechanical station fee for rental equipment.

\section{Model construction}

\subsection{Basic assumptions}

In order to simplify the resource balance optimization model, this paper puts forward the following assumptions when constructing the model:

(1) The total duration is unchanged;

(2) The duration of each process and the logical relationship are unchanged;

(3) Each process in the construction plan cannot be interrupted;

(4) It is assumed that the adjustment of non-critical activities will not cause an increase in the total construction period.

\subsection{Model Construction}

The objective function is:

$$
\min R C=\sum_{x=1}^{X} \sum_{t=1}^{T} R S H_{x, t} \cdot R C H_{x, t}+\sum_{y=1}^{Y} \sum_{t=1}^{T} R S M_{y, t} \cdot R C H_{y, t}
$$

\section{S.t.:}




$$
\begin{aligned}
& R H_{x, t}=\sum_{i=1}^{N} r H_{i, x, t}, \quad R M_{y, t}=\sum_{i=1}^{N} r M_{i, y, t} \\
& r H_{i, x, t}=\left\{\begin{array}{ll}
r H_{i, x} & S_{i} \leq t \leq S_{i}+D_{i} \\
0 & \text { else }
\end{array}, \quad r M_{i, y, t}= \begin{cases}r M_{i, y} & S_{i} \leq t \leq S_{i}+D_{i} \\
0 & \text { else }\end{cases} \right. \\
& R S H_{x, t}=\left|R H_{x, t}-R H C_{x}\right|, \quad R C H_{x, t}= \begin{cases}R C H_{(R H) x, t} & R H_{x, t} \geq R H C_{x} \\
R C H_{(R I) x, t} & R H_{x, t}<R H C_{x}\end{cases} \\
& R S M_{y, t}=\left|R M_{y, t}-R M C_{y}\right|, \quad R C M_{y, t}= \begin{cases}R C M_{(R H) y, t} & R M_{y, t} \geq R M C_{y} \\
R C M_{(R I) y, t} & R M_{y, t}<R M C_{y}\end{cases} \\
& 0 \leq R H C_{x} \leq \sum_{i=1}^{N} D_{i} \cdot r H_{i, x} \quad, \quad 0 \leq R M C_{y} \leq \sum_{i=1}^{N} D_{i} \cdot r M_{i, y}
\end{aligned}
$$

In the formula:

Table 1 List of model variables

\begin{tabular}{|c|l|}
\hline $\mathrm{RC}$ & Total cost of project resource scheduling \\
\hline $\mathrm{T}$ & Project duration \\
\hline $\mathrm{t}$ & Time $\mathrm{t}$ \\
\hline $\mathrm{X}$ & Number of human resources of the project \\
\hline $\mathrm{R}$ & Xth human resources \\
\hline $\mathrm{RCH}_{\mathrm{x}, \mathrm{t}}$ & The xth human resource dispatch volume of the project at time $\mathrm{t}$ \\
\hline$R H_{x, t}$ & The unit cost per unit resource of the xth human resource at the time $\mathrm{t}$ \\
\hline$r H_{i, x, t}$ & Unit i demand for the xth human resource at job t at time $\mathrm{t}$ \\
\hline$r H_{i, x}$ & Unit i demand for the xth human resource in job $\mathrm{i}$ \\
\hline$R S H_{x, t}$ & The xth human resource dispatch volume of the project at time $\mathrm{t}$ \\
\hline$R H C_{x}$ & Regular employment of the xth human resources of the project \\
\hline$R C H_{x, t}$ & The unit cost per unit resource of the xth human resource at the time $\mathrm{t}$ \\
\hline$R C H_{(R H) x, t}$ & $\begin{array}{l}\text { In the RH strategy, the resource cost per unit of the xth human resource at } \\
\text { time } \mathrm{t}\end{array}$ \\
\hline$R C H_{(R I) x, t}$ & $\begin{array}{l}\text { In the RI strategy, the resource cost per unit of the xth human resource at } \\
\text { time } \mathrm{t}\end{array}$ \\
\hline$D_{i}$ & Duration of work i \\
\hline$S_{i}$ & Actual start time of job i \\
\hline$E S_{i}$ & The earliest start time of work i \\
\hline$L S_{i}$ & The latest start time of job i \\
\hline
\end{tabular}

(The variable of mechanical equipment resource $\mathrm{y}$ is same as human resource $\mathrm{x}$ ) 


\section{An example}

In order to prove the validity of the model and algorithm, the experimental examples use the example of the literature ${ }^{[5]}$ to verify the model and method. The study contains 11 tasks, of which Work $\mathrm{A}$ is added to meet the drawing rules of the single-code network plan, and does not take up time and resources. The single code network diagram and resource requirements are shown in the figure1 below.

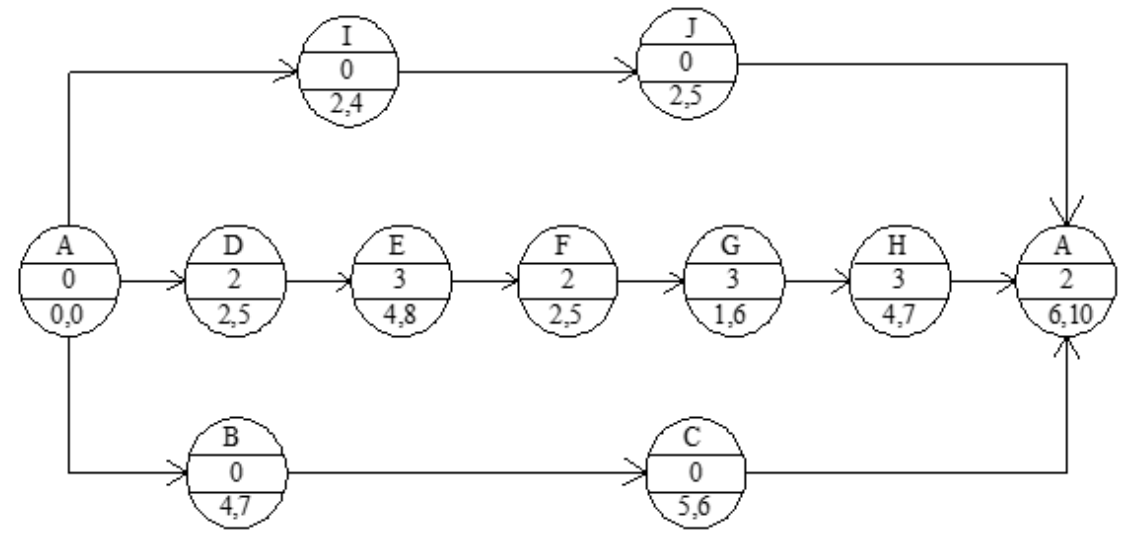

Figure 1 Multi-resource equilibrium optimization model example single code network

At the same time, the scheduling costs of the two resources are as follows:

Table 2 Human resource scheduling data of the example (unit: yuan / day)

\begin{tabular}{|c|c|c|c|c|c|c|}
\hline & $\begin{array}{c}\text { Labor } \\
\text { acquisition } \\
\text { cost }\end{array}$ & $\begin{array}{c}\text { New employee } \\
\text { training costs }\end{array}$ & $\begin{array}{c}\text { Workers' } \\
\text { labor costs }\end{array}$ & $\begin{array}{c}\text { Ergonomic } \\
\text { loss cost }\end{array}$ & $R C H_{(R H) x, t}$ & $R C H_{(R I) x, t}$ \\
\hline $\begin{array}{c}\text { Some kind of } \\
\text { human } \\
\text { resources }\end{array}$ & 50 & 30 & 50 & 10 & 90 & 50 \\
\hline
\end{tabular}

Table 3 Examples of mechanical equipment resource parameters (unit: yuan / day)

\begin{tabular}{|c|c|c|c|c|c|}
\hline Resource type & $\begin{array}{c}\text { Equipment entry } \\
\text { and exit fees }\end{array}$ & $\begin{array}{c}\text { Equipment } \\
\text { installation fee }\end{array}$ & $\begin{array}{c}\text { Equipment } \\
\text { cost }\end{array}$ & $R C M_{(R H) y, t}$ & $R C M_{(R I) y, t}$ \\
\hline $\begin{array}{c}\text { Certain } \\
\text { mechanical } \\
\text { equipment } \\
\text { resources }\end{array}$ & 100 & 30 & 50 & 130 & 50 \\
\hline
\end{tabular}

Table 4 Example to solve partial optimization results

\begin{tabular}{|c|c|c|c|c|c|}
\hline \multirow{2}{*}{$\begin{array}{c}\text { Serial } \\
\text { number }\end{array}$} & Start time of each job & \multicolumn{2}{|c|}{$\begin{array}{c}\text { Regular employment of } \\
\text { resources }\end{array}$} & \multirow{2}{*}{ RC } & $\begin{array}{c}\text { Resource } \\
\text { balance variance }\end{array}$ \\
\cline { 3 - 5 } & & $R H C_{x}$ & $R M C_{y}$ & & 12 \\
\hline 1 & $0,0,6,0,2,5,7,10,4,9,13$ & 6 & 12 & 2890 & 3.41 \\
\hline 2 & $0,0,5,0,2,5,7,10,4,8,13$ & 6 & 12 & 3100 & 3.41 \\
\hline 3 & $0,0,5,0,2,5,7,10,4,8,13$ & 6 & 13 & 5.28 \\
\hline 4 & $0,0,7,0,2,5,7,10,5,4,13$ & 6 & 14 & 3390 & 4.61 \\
\hline 5 & $0,0,5,02,5,7,10,3,8,13$ & 6 & 12 & 3070 & \\
\hline
\end{tabular}


After solving, the optimal value of the objective function is 1930,from the optimization results of the 1,2 and 5 , although the regular consumption of resources is the same, the resource scheduling cost of the first scheme is optimal due to the optimization of resource balance. The above optimization results show the significance of resource balance optimization from the perspective of resource scheduling cost.

This paper analyzes the shortcomings of the multi-resource equalization method of traditional construction projects, and studies the superiority of the problem from the perspective of cost, and introduces the concept of resource scheduling cost, at the same time, the calculation method is given, and the multi-resource equilibrium optimization model is constructed, finally, the example is solved by genetic algorithm. It proves that the resource allocation optimization of construction project from resource scheduling cost is reasonable and accurate, and provides a new idea for solving multi-resource equilibrium optimization of construction projects.

\section{References}

[1] Ding Jiyong, Wang Zhuoyu. Analysis of multi-resource equilibrium problem and its optimization method [J]. Journal of Engineering Management, 2011 (1): 51-55.

[2] Bai Sijun. Heuristic optimization method for multi-resource constrained network planning [J]. Systems Engineering Theory and Practice, 1995 (7): 42-47.

[3] Moncer Hariga,Sameh M El-Sayegh. Cost Optimization Model for the Multiresource Leveling Problem with Allowed Activity Splitting [J]. Journal of Constration Engineering and Management, 2011 (1): 54-56.

[4] TAN Fei,ZHOU Bin. Research on Multi-resource Equilibrium Optimization of Engineering Project Based on Resource Scheduling Fee [J].Project Management Technology,2013,11(02):39-43.

[5] Guo Haibin. Research on resource allocation model of engineering projects [D]. Tianjin University, 2007. 